\title{
PENGARUH FASADE BANGUNAN PADA LINGKUNGAN BINAAN BAGI KORIDOR JALAN DI PERKOTAAN
}

Studi Kasus: Jl. Metro Pondok Indah, Jakarta Selatan

\author{
Rizaldi Lufti \\ Universitas Indraprasta PGRI, Program Studi Arsitektur \\ rizaldi.lufti@gmail.com
}

\begin{abstract}
Jalan Metro Pondok Indah, South Jakarta is one of the main connecting roads between regions located in South Jakarta. In its development there is a phenomenon of building facade diversity that has an impact on the visual quality of the road. Facade buildings at the research site and learn which visual continuity in building facade elements in improving the visual quality of the road in the area. The method used in this research is descriptive research method with qualitative research where data can be obtained through visual observations by decapitating road connections at the study site. The results obtained from this study from the two facade elements of the building along the road in this area which consist of the roof shape and type of openings obtained from Jalan Metro Pondok Indah have a high degree of uniformity and quantity on the second element of the building facade. Get good visual quality. Combination of roads where the two road sections are located in the northern point which has the strongest visual quality.
\end{abstract}

Key Words: Fascade, Built Environment, Street Corridor, Urban

\begin{abstract}
Abstrak: Jalan Metro Pondok Indah, Jakarta Selatan merupakan salah satu jalan penghubung utama antar kawasan yang terletak di bilangan Jakarta Selatan. Dalam perkembangannya terjadi fenomena keragaman elemen fasade bangunan yang berdampak kepada kualitas visual pada jalan tersebut. Penelitian ini bertujuan untuk dapat mengetahui fenomena keragaman jenis dan jumlah elemen fasade bangunan pada lokasi penelitian serta mengetahui sejauh mana kontinuitas visual pada elemen fasade bangunan di dalam mempengaruhi kualitas visual jalan pada kawasan tersebut. Metode yang digunakan dalam penelitian ini adalah metode penelitian deskriptif dengan pendekatan kualitatif dimana data di dapat melalui hasil observasi visual dengan pemenggalan simpul jalan pada lokasi penelitian. Hasil yang didapat dari penelitian ini bahwa dari kedua elemen fasade bangunan di sepanjang jalan pada kawasan tersebut yang terdiri dari bentuk atap dan tipe bukaan didapatkan gambaran bahwa Jalan Metro Pondok Indah memiliki tingkat keseragaman akan jenis dan jumlah yang cukup tinggi pada kedua elemen fasade bangunan yang ada. Sehingga kualitas visualnya cukup baik. Konfigurasi tersebut dihasilkan dari kesimpulan bahwa perbandingan dari penggal jalan dimana penggal jalan dua yang terletak pada titik arah utara yang memiliki kualitas visual terkuat.
\end{abstract}

Kata Kunci: Fasade, Lingkungan Binaan, Koridor Jalan, Perkotaan

\section{PENDAHULUAN}

Pondok Indah merupakan sebuah kawasan yang dikembangkan oleh PT. Metropolitan Kencana. Kawasan ini dibangun pertama kali pada tahun 70 -an. Pondok Indah semakin populer namanya dengan hadirnya Pondok Indah Mall 1 serta tuntasnya proyek Jalan Tol JORR Pondok Pinang - Ciputat pada tahun 2004. Dalam hal ini yang akan di angkat kasusnya adalah pengaruh fasade bangunan pada lingkungan binaan bagi koridor jalan di perkotaan pada studi kasus di Jl. Metro Pondok
Indah. Fenomena akan adanya pengaruh fasade bangunan ini terjadi pada koridor jalan utama yang ada, yaitu di sepanjang koridor Jl. Metro Pondok Indah (pola ribbon) sepanjang $\pm 4 \mathrm{~km}$. Selain itu fungsi fasade bangunan juga sebagai generator bagi kawasan/lingkungan sekitarnya (Trancik, 1986). 


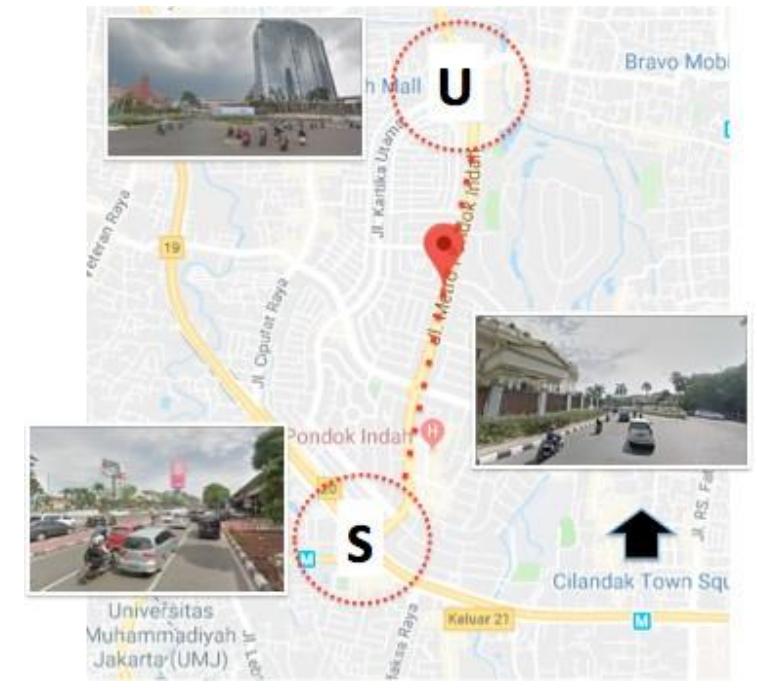

Gambar 1. Jl. Metro Pondok Indah, Jakarta Selatan

Batasan lingkup penelitian ini adalah fasade bangunan yang terletak di sepanjang koridor Jl. Metro Pondok Indah sepanjang $\pm 4 \mathrm{~km}$. Seperti yang terlihat pada Gambar 1.1. diatas.

Rumusan masalah yang ada di ruang koridor jalan Jl. Metro Pondok Indah adalah terjadinya fenomena keragaman elemen fasade dari deretan bangunan yang ada disepanjang koridor jalan tersebut berangkat dari fungsinya masing-masing.

Seiring dengan permasalahan tersebut di atas, maka dapat diajukan pertanyaan penelitian sebagai berikut:

1. Seperti apa tingkat keragaman jenis dan elemen fasade deretan bangunan pada ruang koridor Jl. Metro Pondok Indah, Jakarta Selatan?

2. Sejauh mana tingkat kualitas visual pada ruang koridor Jl. Metro Pondok Indah, Jakarta Selatan?

3. Pada penggal jalan mana yang memberikan pengaruh besar terhadap kualitas visual ruang koridor Jl. Metro Pondok Indah, Jakarta Selatan?

Tujuan dari penelitian ini adalah untuk dapat mengetahui fenomena keragaman jenis dan elemen fasade deretan bangunan pada lokasi penelitian serta mengetahui sejauh mana kualitas visual koridor jalan kolektor sekunder pada kawasan Bintaro.

Manfaat dari penelitian ini bagi ilmu pengetahuan adalah untuk memberikan masukan guna sebagai acuan didalam hal merencanakan dan merancang fasade bangunan disepanjang koridor jalan pada sebuah kawasan permukiman.

\section{METODOLOGI}

Metode penelitian yang digunakan di dalam penelitian ini adalah metode penelitian deskriptif dengan pendekatan kualitatif. Penelitian deskriptif yaitu, penelitian yang dilakukan untuk mengetahui nilai variabel mandiri, baik satu variabel atau lebih (independen) tanpa membuat perbandingan, atau menghubungkan dengan variabel yang lain (Sugiyono, 2012:13).

Kegiatan penelitian ini meliputi pengumpulan data, analisis data, interprestasi data, dan pada akhirnya dirumuskan suatu kesimpulan yang mengacu pada analisis data tersebut.

Sebagai variabel penelitiannya adalah fasade bangunan, yaitu komposisi fasade yang dapat dilihat melalui persyaratan fungsionalnya seperti bidang atap dan bukaan (pintu dan jendela) (Krier, 1988:122). Dari hasil analisis fasade bangunan akan didapatkan seperti apa kondisi fasade bangunan dan subvariabel apa yang mendominasi koridor $\mathrm{Jl}$. Metro Pondok Indah, Jakarta Selatan.

Tabel 1. Variabel dan Instrumen Penelitian untuk Fasade Bangunan

\begin{tabular}{|c|l|l|c|}
\hline $\begin{array}{c}\text { Unsur } \\
\text { Pengamatan }\end{array}$ & \multicolumn{1}{|c|}{ Variabel } & \multicolumn{1}{|c|}{ Sub Variabel } & Instrumen \\
\hline \hline \multirow{3}{*}{ Fasade Bangunan } & Atap & Miring & \multirow{2}{*}{ Obervasi Visual } \\
\cline { 2 - 3 } & & Datar & \\
\cline { 2 - 3 } & Bukaan & Klasik & Obervasi Visual \\
\cline { 2 - 4 } & & Modern & \\
\hline
\end{tabular}

Penelitian ini mengambil studi di sepanjang koridor Jl. Metro Pondok Indah (lihat Tabel 1). Dalam penelitian ini variabel yang digunakan adalah fasade bangunan yang berada di koridor jalan tersebut.

Untuk variabel kedua adalah
koridor jalan. Spesifikasi dan
karakteristik fisik dan non fisik pada
suatu koridor jalan sangat besar
pengaruhnya dalam menentukan wajah
dan bentuk koridor itu sendiri.
Keberadaan suatu koridor sebagai
pembentuk arsitektur kawasan kota tidak


akan lepas dari elemen-elemen pembentuk citra koridor tersebut (Krier, 1979: 61), yaitu:

1. Wujud bangunan, merupakan wajah atau tampak dan bentuk bangunan yang ada di sepanjang koridor jalan. Wajah dan bentuk bangunan tersebut merupakan tampak keseluruhan dari suatu koridor yang mampu mewujudkan identitas dan citra arsitektur suatu kawasan.

2. Figure ground, merupakan hubungan penggunaan lahan untuk massa bangunan dan ruang terbuka. Struktur tata ruang kota menurut Trancik (1986: 101) terdiri dari dua elemen pokok, yaitu massa bangunan kawasan (urban solid) dan ruang terbuka kawasan (urban void). Kedua elemen tersebut membentuk pola padat rongga ruang kota yang memperlihatkan struktur ruang kawasan kota dengan jelas.

3. Street and Pedestrian ways, merupakan jalur jalan pergerakan kendaraan dan bagi pejalan kaki yang dilengkapi dengan parkir, elemen perabot jalan (street furniture), tata tanda (signage), dan pengaturan vegetasi sehingga mampu menyatu terhadap lingkungan. Koridor jalan dan jalur pejalan kaki merupakan ruang pergerakan linear sebagai sarana sirkulasi dan aktivitas manusia dengan skala padat.

Tabel 2. Variabel dan Instrumen Penelitian untuk Koridor Jalan

\begin{tabular}{|c|l|l|c|}
\hline $\begin{array}{c}\text { Unsur } \\
\text { Pengamatan }\end{array}$ & \multicolumn{1}{|c|}{ Variabel } & Sub Variabel & \multirow{2}{*}{ Instrumen } \\
\hline \hline \multirow{4}{*}{ Koridor Jalan } & Wujud Bangunan & Klasik & \multirow{2}{*}{ Obervasi Visual } \\
\cline { 2 - 3 } & & Modern & \\
\cline { 2 - 3 } & Figure Ground & Urban Solid & \multirow{2}{*}{ Obervasi Visual } \\
\cline { 2 - 3 } & & Urban Void & \\
\cline { 2 - 3 } & Street \& & Street Furniture & \multirow{2}{*}{ Obervasi Visual } \\
\cline { 2 - 4 } & Pedestrian Ways & Signage & \\
\hline
\end{tabular}

Dalam penelitian ini variabel yang digunakan adalah koridor jalan yang ada pada lokasi penelitian.

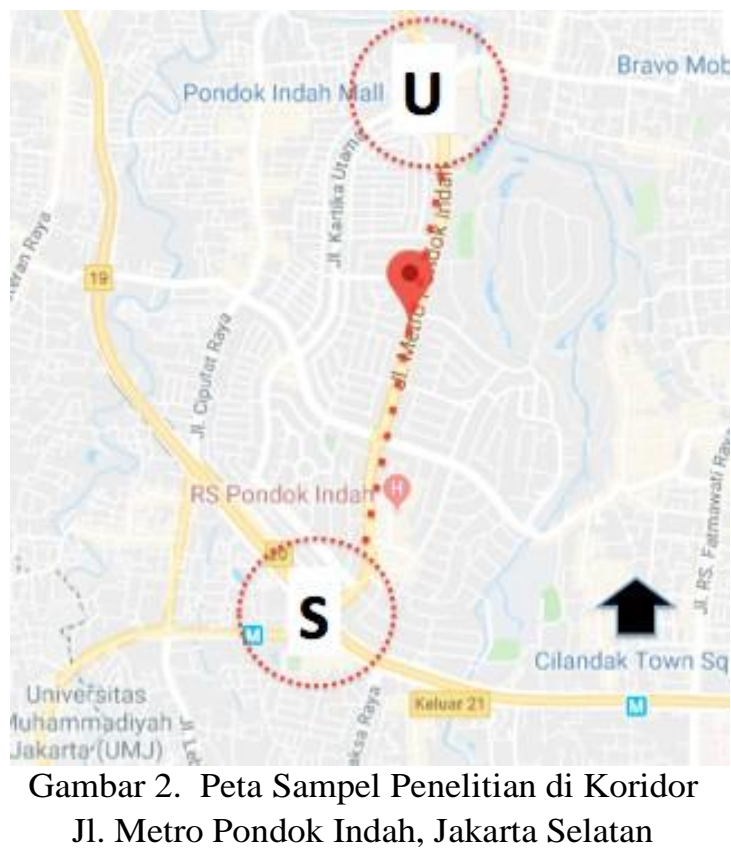

Data-data dikumpulkan dengan menggunakan instrumen yang telah disiapkan dan ditentukan sebelumnya. Data primer dikumpulkan dengan cara melakukan Observasi Visual yang dilakukan pada koridor Jl. Metro Pondok Indah, Jakarta Selatan.

Data sekunder diperoleh dengan cara mengumpulkan data yang berhubungan dengan permasalahan yang ada yaitu mengumpulkan beberapa teori dari para ahli dan informasi dari pihak pengembang terkait dengan studi penelitian.

Metode analisis dilakukan dengan cara deskriptif melalui pendekatan kualitatif dalam bentuk tabulasi.

\section{HASIL DAN PEMBAHASAN}

Lokasi penelitian merupakan koridor Jl. Metro Pondok Indah, Jakarta Selatan yang membentang sepanjang $\pm 4 \mathrm{~km}$ (lihat Gambar 2). Sepanjang koridor jalan ini diisi oleh deretan bangunan yang didominasi oleh fungsi komersil (data primer, peneliti 2019). Berdasarkan data dari Pengembang, pada awalnya kawasan ini khususnya koridor jalan diperuntukkan untuk area hunian. Akan tetapi, kawasan ini berkembang menjadi kawasan komersil karena adanya stimulan ekonomi dari kawasan sekitarnya. Meskipun demikian, hingga saat ini masih terdapat beberapa bangunan yang mempertahankan fungsinya 
sebagai hunian. Perkembangan inilah yang menjadi salah satu penyebab munculnya keragaman fasade bangunan yang mengisi koridor ruang Jl. Metro Pondok Indah, Jakarta Selatan.

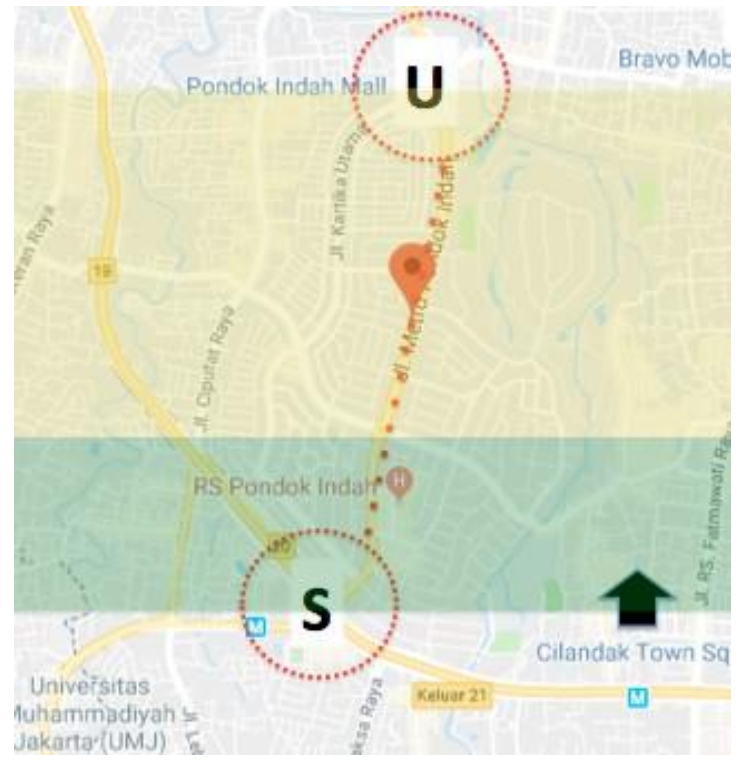

Gambar 3. Jl. Metro Pondok Indah, Jakarta Selatan

Berikut ini adalah hasil temuan dari observasi di lapangan berupa foto fasade bangunan di sepanjang Jl. Metro Pondok Indah, Jakarta Selatan.

Untuk memudahkan penyajian hasil temuan observasi, maka Jl. Metro Pondok Indah sepanjang $\pm 4 \mathrm{~km}$ ini dibagi menjadi 2 penggal jalan (lihat gambar 3). Penggal jalan ini dibuat mengambil acuan pada simpul jalan. Simpul jalan dipilih sebagai media penggal jalan karena merupakan titik pemisah antar fasade bangunan oleh ruang jalan. Peta kunci digunakan untuk memperlihatkan posisi penggal jalan serta jalur pengamatan secara keseluruhan. Setiap penggal jalan, diamati fasade bangunannya, baik di sisi kiri maupun kanan jalan dan disajikan sejajar sesuai posisi bangunan yang saling berhadapan. Hasil temuan observasi visual ini bermaksud memperlihatkan seperti apa kondisi fasade bangunan di sepanjang Jl. Metro Pondok Indah, Jakarta Selatan sebelum dilanjutkan ke tahap analisis.

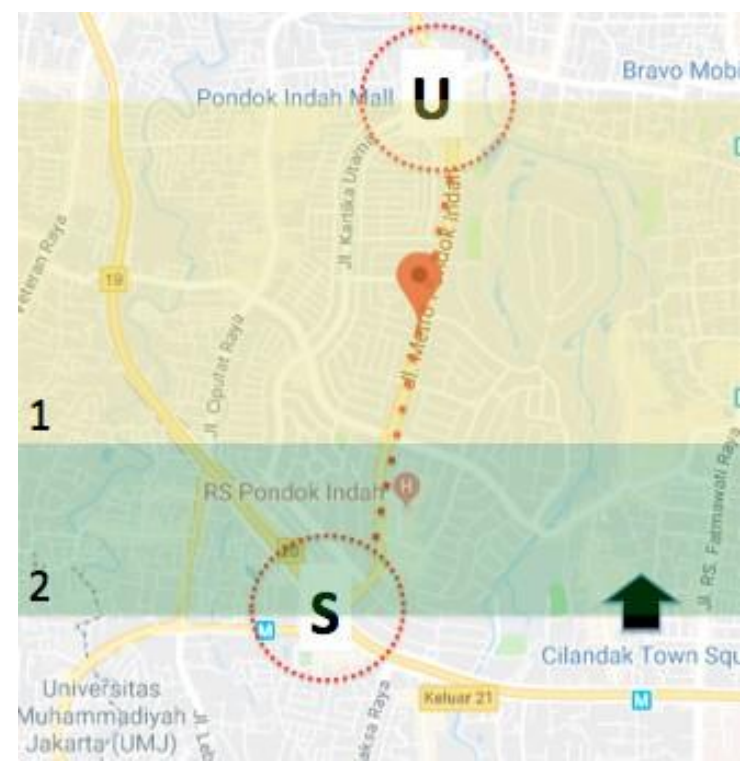

Gambar 4. Pembagian Penggal Jalan pada Jl. Metro Pondok Indah, Jakarta Selatan

Setelah memetakan hasil temuan fasade bangunan, selanjutnya temuan tersebut dianalisis menggunakan unsur fasade bangunan dari teori Robb Krier, 1988. Untuk memudahkan analisis, hasil temuan pengamatan yang berupa foto lapangan diterjemahkan dalam bentuk gambar citra grafis menggunakan skala nominal berupa coding sesuai subvariabel yang sudah ditentukan (lihat Tabel 3). penggunaan coding ini untuk menyederhanakan hasil temuan fasade bangunan agar lebih muda dipahami secara visual.

Tabel 3 Coding Sub-Variabel Fasade Bangunan

\begin{tabular}{|c|c|c|c|}
\hline $\begin{array}{c}\text { Unsur } \\
\text { Pengamatan }\end{array}$ & Variabel & Sub Variabel & Coding \\
\hline \hline \multirow{4}{*}{ Fasade Bangunan } & & Miring & \\
\cline { 3 - 4 } & \multirow{3}{*}{ Atap } & Datar & \\
\cline { 3 - 4 } & & Klasik & \\
\cline { 3 - 4 } & \multirow{3}{*}{ Bukaan } & Modern & \\
\cline { 3 - 4 } & & & \\
\hline
\end{tabular}

Setelah melakukan pengamatan visual per penggal jalan sebanyak dua penggal pengamatan, selanjutnya kedua hasil pengamatan diakumulasi untuk melihat keragaman fasade bangunan sepanjang \pm 4 
km Jl. Metro Pondok Indah, Jakarta Selatan seperti yang terlihat pada Gambar 5 di bawah ini:

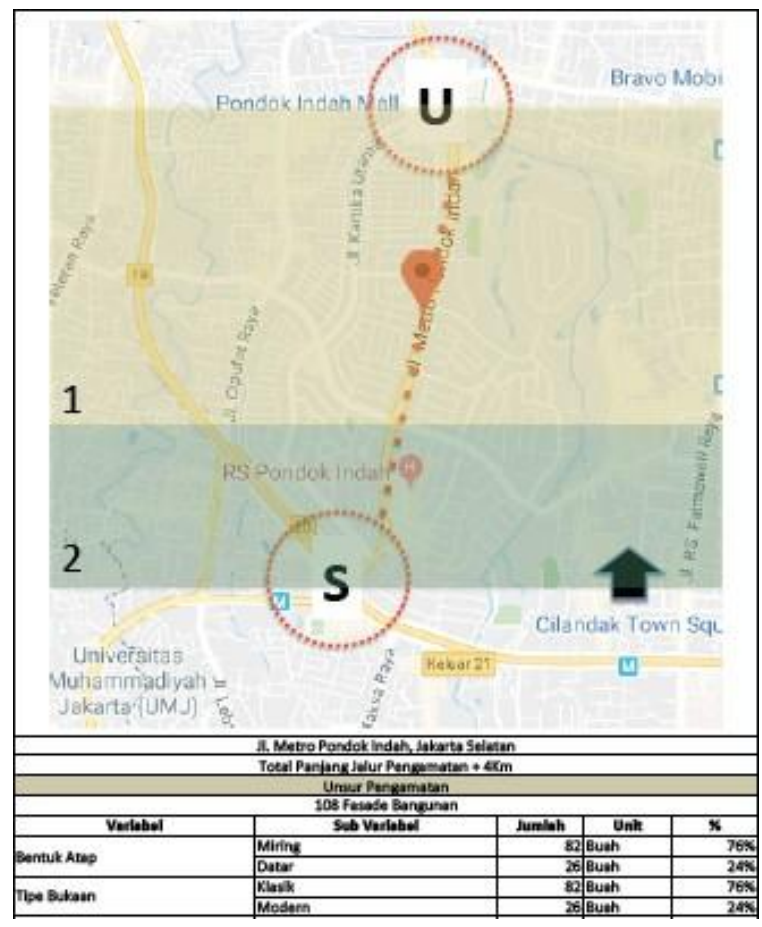

Gambar 5 Hasil Analisis Pengamatan Fasade Bangunan pada Jl. Metro Pondok Indah, Jakarta Selatan

Hasil dari Gambar 6 kemudian ditampilkan dalam bentuk pie chart untuk memperlihatkan secara visual perbandingan prosentase dari tiap subvariabel.

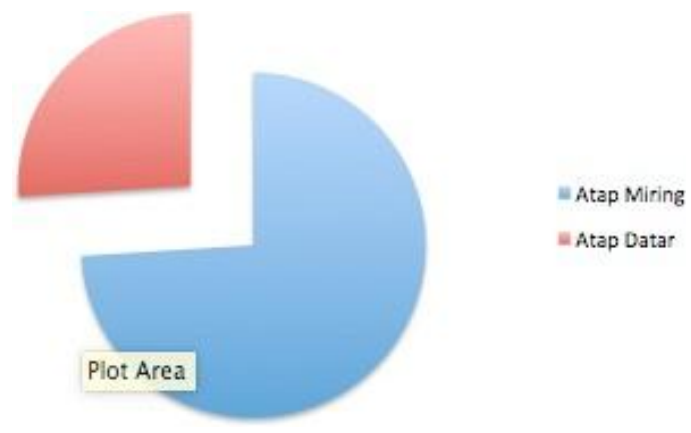

Gambar 6. Diagram Perbandingan SubVariabel Atap

Pada gambar 7 di atas dapat terlihat keseragaman fasade bangunan pada penggunaan atap miring sebesar $74 \%$ di $\mathrm{Jl}$. Metro Pondok Indah, Jakarta Selatan.

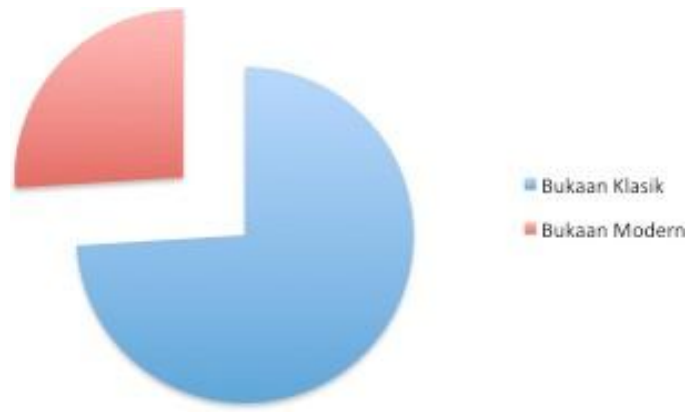

Gambar 7. Diagram Perbandingan Sub-Variabel Bukaan

Bagian fasade bangunan di Jl. Metro Pondok Indah, Jakarta Selatan cenderung lebih banyak pada adanya bukaan klasik dengan prosentase sebesar $74 \%$.

Hasil analisis per penggal jalan di atas kemudian dibandingkan dalam bentuk diagram batang untuk melihat penggal jalan mana yang paling dominan dalam lingkup penelitian pada kedua elemen fasade yang ada.

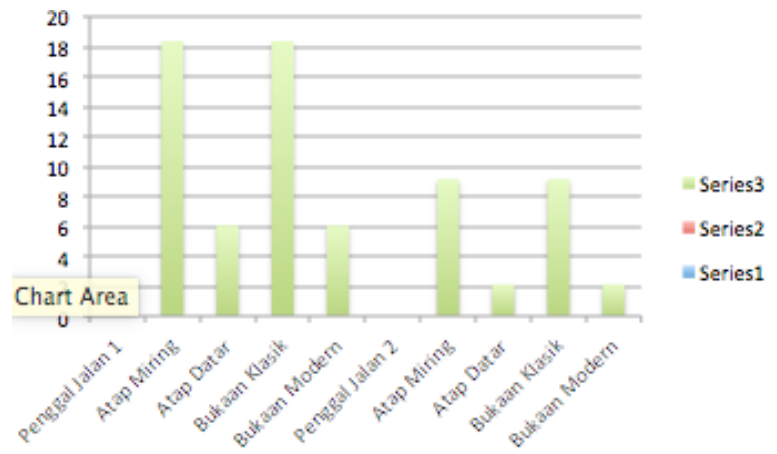

Gambar 8. Diagram Perbandingan Sub-Variabel Penggal Jalan

Dari grafik di atas (lihat gambar 8) terlihat bahwa hasil analisis dan pengamatan di penggal jalan satu yang mendominasi prosentase sub-variabel fasade bangunan dibandingkan penggal jalan dua. Penggal jalan satu terlihat dominan pada elemen bangunan bentuk atap miring dan bukaan klasik masingmasing sebesar $18.36 \%$, karena pada penggal jalan ini bangunan masih didominasi oleh fungsi hunian. 
Dari kedua elemen fasade bangunan tersebut di atas, didapatkan gambaran bahwa ruang koridor Jl. Metro Pondok Indah, Jakarta Selatan masih memiliki kontinuitas serta kualitas visual yang baik karena adanya tingkat keseragaman yang tinggi.

\section{KESIMPULAN}

Setelah melakukan pengamatan dan analisis dapat disimpulkan bahwa elemen fasade bangunan di Jl. Metro Pondok Indah, Jakarta Selatan sebagai berikut:

Penggunaan $74 \%$ untuk Atap miring dan Bukaan Klasik. Penggunaan kedua elemen diatas memunculkan karakter arsitektur tropis pada sepanjang Jl. Metro Pondok Indah, Jakarta Selatan.

Dari kedua elemen fasade bangunan tersebut terdapat keseragaman pada $74 \%$ untuk mainsmasing Atap miring dan Bukaan Klasik, didapatkan gambaran bahwa ruang koridor Jl. Metro Pondok Indah, Jakarta Selatan memiliki kontinuitas visual yang baik.

Penggal jalan satu merupakan penggal jalan yang memiliki pengaruh besar terhadap kualitas visual ruang koridor Jl. Metro Pondok Indah, Jakarta Selatan. Hal ini disebabkan oleh penggal jalan satu ini memiliki tingkat keseragaman yang tinggi pada penggunaan elemen fasade berupa atap miring dan bukaan klasik.

\section{DAFTAR PUSTAKA}

Arnheiim, Rudolf. 1969. "Visual Thinking”. University of California Press.

Ching, D.K., Francis. 1985. “Architectural Graphics". Paperback.

Ching, D.K., Francis. 1996. "Architecture: Form, Space and Order".

Paperback.

Krier, Rob. 1983. "Element of Architecture". London. AD Publication.

Krier, Rob. $1988 . \quad$ "Architectural Composition”, dalam versi bahasa Indonesia diterjemahkan oleh Ir. Effendi Setiadharma, dkk. Penerbit Erlangga. Jakarta.

Rapoport, Amos. 1982. "The Meaning of the Built Environment: A Nonverbal Communication Approach' . University of Arizona Press.
Sanoff, Henry . 1991. "Visual Research Methods in Design". Hardcover.

Trancik, Roger, "Finding Lost Space", Van Nostrand Reinhold Comp., New York, 1986.

Winandari, Ririk, 2010. "Karakter Arsitektur Kota". Penerbit Universitas Trisakti.

Zahnd, Markus. 1999. "Perancangan kota secara terpadu: Teori perancangan kota dan penerapannya". Yogyakarta: Kanisius. 